\title{
DETC2021-69629
}

\section{DESIGN FOR PRODUCT CIRCULARITY: CIRCULAR ECONOMY INDICATORS WITH TOOLS MAPPED ALONG THE ENGINEERING DESIGN PROCESS}

\author{
Michael Saidani ${ }^{1}$, Harrison Kim \\ Department of Industrial and Enterprise Systems Engineering, \\ University of Illinois at Urbana-Champaign, Illinois, 61801, USA
}

\begin{abstract}
Monitoring the circularity potential of products and materials is key to ensure environmental savings and economic profitability of circular economy loops, such as reuse, remanufacturing, or recycling. The choices and decisions made during the product design phase have a major influence and impact on the circularity performance of products. While numerous indicators and tools have been recently developed to assess, manage, and accelerate the transition to a more circular economy, their application and usability during the early design phases of products are often overlooked. Based on a screening of several tens of circular economy indicators, the present research work identified twelve product-centric circularity indicators, each of them coming with a computational tool, to be deployed during the design process in order to improve the circularity potential of products. To help designers and engineers selecting the appropriate solution, these circularity indicators and tools are positioned on a generic five-step design process, namely: requirements definition, conceptual design, detailed design, designs comparison, product monitoring and communication. Concrete examples are given on how these indicators and their assessment framework can support the design of more circular products. Current shortcomings of available approaches are finally highlighted and discussed (such as the lack of c-indicators for the detailed design phase or linkage with computer-aided design software) for an augmented integration of such promising circularity indicators and their associated tools within the design and development process of products.
\end{abstract}

Keywords: Design for circular economy, circularity indicators, assessment tools, product design, design process.

\section{NOMENCLATURE}

Here are the acronyms of the twelve circularity indicators and their associated tools mapped along the design process:

$\begin{array}{ll}\text { CC } & \text { Circularity Calculator } \\ \text { CCET } & \text { Concept Circularity Evaluation Tool } \\ \text { CEIP } & \text { Circular Economy Indicator Prototype } \\ \text { CET } & \text { Circular Economy Toolkit } \\ \text { CIAM } & \text { Circular Index from CirculAbility Model } \\ \text { CP } & \text { Circular Pathfinder } \\ \text { CPI } & \text { Circularity Potential Indicator } \\ \text { MCI } & \text { Material Circularity Indicator } \\ \text { MCPD } & \text { Material Circularity in Product Design } \\ \text { MDI } & \text { Material Durability Indicator } \\ \text { PCI } & \text { Product Circularity Indictor } \\ \text { RPI } & \text { Reuse Potential Indicator }\end{array}$

\section{INTRODUCTION}

The current transition towards a circular economy increasingly supported in the last few years by researchers, environmental organizations, and policy-makers - could advance the achievements of the sustainable development goals (SDGs) set up by the United Nations [1]. Closing-the-loop on industrial processes and products can contribute to more sustainable consumption and production patterns (SDG 12), as well as to fight against climate change (SDG 13) by mitigating the carbon emission and energy consumption due to the extraction and processing of primary raw materials. The way products are designed plays a crucial role in the actual circularity performance of products and materials all along the value chain [2]. Indeed, the circularity potential of a given product is highly dependent on the choices and decisions taken during the design

\footnotetext{
${ }^{1}$ Contact author: msaidani@illinois.edu
} 
process, where product requirements are defined, concepts generated, functional architectures fixed, and materials selected. Having the appropriate indicators to quantify and adjust the circularity potential of products is thus essential to ensure the desired performance, and recently developed circularity indicators coming with web-based or Excel-based tools could help put numbers to this compound concept of product circularity performance for design practitioners [3].

The integration of $\mathrm{Re}-\mathrm{X}$ approach or design for circularity tools is crucial to advance both the sustainable manufacturing and remanufacturing of products [4, 5]. Indeed, design for circularity aims to facilitate the reinsertion of products, components, and materials in adequate circular economy loops such as maintenance, reuse, remanufacturing, or recycling loops [6]. Note also that circular design was mentioned in a 2017 Communication from the European Commission as a key in implementing the Circular Economy Action Plan. At the same time, a growing number of circularity indicators has been developed recently to monitor the circular economy transition. Though, their actual applicability and integration within the product design process have yet to be further exploited. Therefore, the objective of this research is to help researchers and practitioners - such as designers, materials engineers, product development managers - better situate and navigate the circular economy-related indicators available to be deployed during the design and development of products.

Product circularity indicators - c-indicators, hereafter - can be defined as quantitative or qualitative factors or variables that provide reliable and straightforward means [7] to assess and monitor the performance of products (including components and materials) in a circular economy [8]. While a previous research work has started to question the potential contribution and utility of four circularity indicators as tools to guide the design and development of circular-ready products [9], the present piece of work identified twelve c-indicators coming with computational tools (among the pool of several tens of circular economy indicators) that could be deployed during at least one of the steps of the design process. These c-indicators are notably positioned against a generic five-step engineering design process, namely: (i) requirements definition, (ii) conceptual design, (iii) detailed design, (iv) designs comparison, and (v) product monitoring and communication. Practical examples are given on how such product-centric c-indicators and their assessment framework, can be used to design or re-design circular-oriented products, i.e., products with a high circularity potential.

\section{MATERIALS AND METHODS}

This section details all materials and methods that have been used to come up with a selection of twelve circularity indicators with tools and to map them along the design process.

\subsection{Research approach}

To investigate extensively and systematically on how cindicators can support the development of circular design, this research builds first on previous works identifying, reviewing, and classifying circular economy-related indicators, and then dives further into specific product-level c-indicators coming with tools (see Table 1) that might have been developed more recently or non-captured in previous works.

TABLE 1: SYSTEMATIC SEARCH FOR AD HOC C-INDICATORS

\begin{tabular}{|l|l|}
\hline Criteria & Search item for filtering \\
\hline Keywords & $\begin{array}{l}\text { circular economy OR circularity AND } \\
\text { \{indicator OR index OR metric OR } \\
\text { assessment OR evaluation OR measure\} } \\
\text { AND \{product OR component OR material\} } \\
\text { AND \{tool OR spreadsheet OR web-based\} }\end{array}$ \\
\hline $\begin{array}{l}\text { Search } \\
\text { engines }\end{array}$ & $\begin{array}{l}\text { Google Scholar (for academic publications), } \\
\text { Google (for grey literature) }\end{array}$ \\
\hline Language & English \\
\hline Scope & International (worldwide) \\
\hline Time & Up to January 2021 \\
\hline
\end{tabular}

As illustrated in Table 1 and Figure 1, a first filter is used to only consider the c-indicators dealing with the micro-level of circular economy implementation, i.e., at a product, component, or material level [10]. Next, a second filter enables to only keep the c-indicators that are associated with a computational tool (web-based or Excel-based) in order to facilitate their computation by practitioners. Finally, these c-indicators have been examined thoroughly to be positioned on the $\operatorname{step}(\mathrm{s})$ where they could bring the most relevant quantitative guidance along the design process, as well as to provide concrete examples on how they can be deployed to design more circular products.

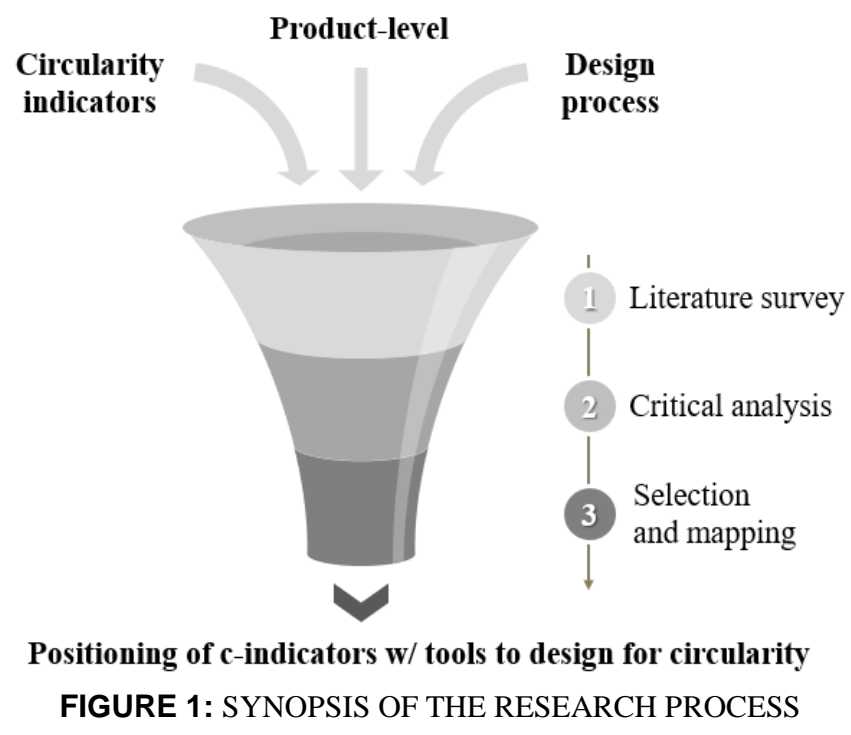

Note that newly developed c-indicators that only comes with (often complex) written formulas in papers are out of the scope of this research as it aims to provide designers and engineers with easy-to-deploy c-indicators. As such, examples of product-level c-indicators not considered in this paper are the following: the Circularity and Longevity Indicators [11], the Product-Level Circularity Metric [12], or the multi-criteria evaluation method of Product-Level Circularity Strategies [13]. C-indicators that 
focus on very specific aspects of the circularity performance of products are also filtered out to ensure a holistic vision of the circular economy during the design and development phases. As achieving a circular economy requires a systemic shift considering the entire product lifecycle as early as the design phase, all the possible R-strategies should receive adequate attention (e.g., recycling is just one part of the solution, among reduce, reuse, refurbished, remanufacturing, etc.) $[14,15]$. This is, for instance, the case of the "Ease of Disassembly Metric" [16]. A similar exclusion criterion is applied for sector-specific c-indicators to ensure broader applicability of the c-indicators recommended in this paper. This is, for instance, the case of ta new version of the Material Circularity Indicator of the Ellen MacArthur Foundation, augmented specifically for bio-based and biodegradable products [17], or of the Madaster Circularity Indicator to assess the level of circularity of buildings [18].

\subsection{Literature survey: engineering design process and product-level circularity indicators}

Different authors have proposed different phases when modeling the engineering design process, resulting in slight variations between these design process models [19]. To Pahl and Beitz [20], the engineering design process is composed of the following steps: task clarification (including needs identification and definition), conceptual design, embodiment design, detailed design. To Ulrich et al. [21], the early stage of product design and development encompasses planning, concept development; and the later stages of product design and development deal with system-level design, detailed, testing and refinement, and production ramp-up. In the present study, a simple and generalized five-step product design process is considered for mapping the suitable circularity indicators on it, namely: (i) requirements definition, (ii) conceptual design (or concept generation), (iii) detailed design, (iv) designs comparison, and (v) product monitoring and communication.

Recently, Saidani et al. [9] started to position four cindicators - the Material Circularity Indicator (MCI), Circular Economy Toolkit (CET), Circularity Potential Indicator (CPI), and Circular Economy Indicator Prototype (CEIP) - among the pool of eco-design methods and tools, including life cycle assessment, quality function deployment eco-based tools, design for environment matrix, or eco-design checklists [22]. These four c-indicators were mapped on a two-dimensional chart, with the $y$-axis indicating the complexity level or time required to use the tool, and the $\mathrm{x}$-axis representing the different steps of the product design process. Kamp Albæk et al. [2] have also identified and reviewed four circularity assessment tools that can be used for evaluating product circularity at the concept level or at the early development stage, namely: the CEIP, CET, CPI, and Circular Pathfinder (CP).

In parallel, scholars kept identifying and analyzing newly developed circular economy indicators at different scales [23], as there is currently no standardized approach or indicator to measure (product) circularity [10]. For instance, Kristensen and Mosgaard [10] made a critical analysis on 30 indicators aiming to measure micro-level circularity, showing that most of these c- indicators focused on the outer circle of a circular economy (e.g., recycling), while a limited number focused on the inner circles (e.g., production process). In this line, de Oliveira et al. [23] highlighted that the majority of product-centric c-indicators are environmentally-driven indicators focusing on material and resource recovery strategies. Lastly, by reviewing 74 academic approaches, methods, and tools developed by academics to assess circular economy at the micro-level, Roos Lindgreen et al. [24] suggested a closer collaboration between scholars and practitioners to consider end-user needs in the design of circularity assessment approaches. To Dokter et al. [3], the successful implementation of the circular economy relies on extensive collaboration between all actors involved all along the design process stages.

\section{RESULTS AND DISCUSSION}

In this section, the circularity indicators coming with tools that are particularly fit to be deployed during the design process are first identified and introduced (sub-section 3.1). Then, these $\mathrm{c}$-indicators are positioned along a generic five-step engineering design process to facilitate the selection of the most appropriate indicator(s) and tool(s) according to the practitioner's need (subsection 3.2). Finally, concrete examples of the qualitative and quantitative insights generated by these c-indicators to design more circular products are given and discussed (sub-section 3.3).

\subsection{Ad hoc c-indicators with tools for product design}

Following the research methodology displayed in subsection 2.1, twelve c-indicators have been identified as potentially relevant and practical to guide the circular design of products (listed and described hereafter, by alphabetical order):

1. Circularity Calculator (CC) [25]: The CC aims to help designers that work in the fuzzy front end of product development to understanding how design decisions influence the degree of circularity of resource flows and potential value capture within product-service systems. It can be used by cross-department product development teams to compare different circular design scenarios and guide them through consequential decisions. Interestingly, the CC is embedded in a webbased platform that calculates and displays the potential circularity and captures the value of different design strategies in a graphical format.

2. Concept Circularity Evaluation Tool (CCET) [2]: The CCET aims to support the evaluation of alternative product concepts in terms of their circularity potential in the early stages of product design and development. It consists of circular guidelines where a Circularity Potential Score is attributed to each of the guidelines, and a Total Circularity Potential Score which is the sum of the scores for each guideline. The Excel-based CCET has notably been experimented with at four manufacturing companies.

3. Circular Economy Indicator Prototype (CEIP) [26]: The CEIP is intended to be used by manufacturing and/or retail companies of tangible goods to monitor the 
intrinsic circularity performance of the products they develop and/or sell. It comes with an Excel-based tool to score points for different phases of the product lifecycle based on the answers given to 15 questions.

4. Circular Economy Toolkit (CET) [27]: The CET is an online questionnaire-based assessment tool analyzing the circularity performance of products and services sold by a company. Following a checklist of circular economy principles, it gives guidance on potential improvement areas, with indications (opportunity and feasibility) of which areas the product performs well in terms of circularity (e.g., design, manufacture, and distribute phases).

5. Circular Index from CirculAbility Model (CIAM) [28]: The CIAM is an online circularity measurement model aiming at evaluating the circularity of a product throughout its value chain. The result of the model is a circularity index, which is calculated based on a combination of two components: circularity of flow, and circularity of use. Monitoring the circularity of flow during the design process is key as it mainly covers decisions related to the origin and intended use of materials and energy, such as the percentage of materials and energy from renewable or non-renewable sources, as well as the recycled or reused origin of materials or components.

6. Circular Pathfinder (CP) [29]: The CP is a time-efficient web-based tool indicating the most commendable circular pathways for the products that companies design and manufacture. Based on high-level questions (related to the product type, product customer interactions, lifetime, and user needs), it is mainly applicable in the early design stages of new product development (i.e., project scoping and requirements definition) to figure out the most promising product strategies for improving circularity.

7. Circularity Potential Indicator (CPI) [30]: The CPI aims at evaluating and improving the circularity potential of products during the design phases. The CPI is computed through a guided questionnaire of twenty attributes impacting the circularity performance of a product, following the four building blocks of a CE defined by the Ellen MacArthur Foundation, namely: (i) circular product design, (ii) new business models, (iii) reverse systems, and (iv) enablers and system conditions. The CPI is embedded in both Excel-based and web-based tools.

8. Material Circularity Indicator (MCI) [31]: The MCI, developed by the Ellen MacArthur Foundation, combines, in a single indicator, aspects of lifetime and intensity of use with the proportion of recycled material and the share of materials in a product that can be recycled. The MCI is associated with a dynamic calculation spreadsheet and is applicable at a material, product, or company level.
9. Material Circularity in Product Design (MCPD) [32]: The MCPD is an Excel-based indicator of circular material value, including four design variables (design yield, functional unit, mass, and material degradation after use) and five network variables (price, market risk, material criticality, transformation process yield coefficient, and end-of-life scenario functional degradation coefficient). As such, it conveys not only the impacts of design choices in material flows considering multiple end-of-life scenarios and related recovery options, but also incorporates material flow information in the estimation of material value, as well as a risk and criticality assessment.

10. Material Durability Indicator (MDI) [33]: The MDI is an indicator for selecting materials considering mechanical- and chemical-related parameters while monitoring the potential circularity performance of a technical product. It can potentially be applied to any engineering material, and is particularly relevant during the early phases of the design process for requirements definition, as well as for accurate materials selection, towards extending product lifespan.

11. Product Circularity Indicator (PCI) [34]: The PCI is a computational tool aiming at measuring the circularity potential of products in supply chains. It has been developed as an augmented version of the MCI, and notably applied to design and monitor the circularity performance of washing machines.

12. Reuse Potential Indicator (RPI) [35]: The RPI aims at supporting decision-making during the design process to use "resource-like" materials instead of "waste-like" materials, and thus improve the circularity performance of products. It is linked to a quantitative computational tool to assist decision-makers in setting quantitative material reuse targets.

\subsection{Positioning along the design process}

To make proper usage of these product-centric circularity indicators and get appropriate guidance during the design process, it is critical to know which c-indicators are the most commendable for specific design phases. To Kamp Albæk et al. [3], the c-indicators selection significantly depends on which role such an indicator and its associated tool should have and the design step(s) in which it is applied. Through a more in-depth analysis of these 12 c-indicators, we proposed the first positioning of these indicators along a generalized five-step engineering process, as shown in Table 2 , where a " $x$ " indicates its main application area, and a "(x)" indicates the secondary purposes of such indicators. Overall, it can be noted that while numerous c-indicators are particularly useful to set up circular requirements (concrete examples are given in the next subsection) or to compare alternatives in terms of circularity potential, few c-indicators and their associated computational tools currently support the detailed design. Meanwhile, several c-indicators and their associated tools are insightful resources for the conceptual and preliminary design phases to ideate and/or 
generate high-level designs that include circular economy principles.

TABLE 2: C-INDICATORS FIT FOR THE DESIGN PROCESS

\begin{tabular}{|l|l|l|l|l|l|}
\hline C-Ind. & $\begin{array}{l}\text { Rqmts. } \\
\text { definition }\end{array}$ & $\begin{array}{l}\text { Conceptual } \\
\text { design }\end{array}$ & $\begin{array}{l}\text { Detailed } \\
\text { design }\end{array}$ & $\begin{array}{l}\text { Design } \\
\text { compar. }\end{array}$ & $\begin{array}{l}\text { Product } \\
\text { monitor }\end{array}$ \\
\hline MCPD & $(\mathrm{x})$ & $(\mathrm{x})$ & $\mathrm{x}$ & $\mathrm{x})$ & $(\mathrm{x})$ \\
\hline MDI & $\mathrm{x}$ & & $\mathrm{x}$ & $(\mathrm{x})$ & \\
\hline CIAM & $\mathrm{x}$ & $(\mathrm{x})$ & & $\mathrm{x})$ & \\
\hline RPI & $(\mathrm{x})$ & & & $\mathrm{x}$ & $(\mathrm{x})$ \\
\hline PCI & $(\mathrm{x})$ & & & $\mathrm{x}$ & $(\mathrm{x})$ \\
\hline CCET & $\mathrm{x}$ & $\mathrm{x}$ & $(\mathrm{x})$ & $\mathrm{x}$ & \\
\hline CEIP & $(\mathrm{x})$ & $(\mathrm{x})$ & & $\mathrm{x}$ & $(\mathrm{x})$ \\
\hline CPI & $\mathrm{x}$ & $\mathrm{x}$ & $(\mathrm{x})$ & $\mathrm{x}$ & $(\mathrm{x})$ \\
\hline CET & $\mathrm{x}$ & $(\mathrm{x})$ & & & \\
\hline MCI & & & & $(\mathrm{x})$ & $\mathrm{x}$ \\
\hline CC & & & & $(\mathrm{x})$ & $\mathrm{x}$ \\
\hline CP & $\mathrm{x}$ & $(\mathrm{x})$ & & & \\
\hline
\end{tabular}

In addition to their applicability to particular phases of the product design process, informing on the usability and userfriendliness of such c-indicators for practitioners non-necessarily expert to the circular economy concept is also key to foster their adoption. In this line, an interactive web-based tool is under development to visualize and identify rapidly the most adequate c-indicator(s) adapted to the user's needs. As illustrated in Figure 2 , this web-based tool is expected to be presented at the Design Tool Showcase of the present conference. The current version of the tool (still under development) mapped on a two-dimensional graph the ad hoc c-indicators and their associated tools, where the $\mathrm{x}$-axis represents the engineering design process (from early phase to late phase), and the y-axis the level of details or time required to compute these $\mathrm{c}$-indicators.

For instance, on the one hand, the CEIP or the CET enable simple calculations and can be applied with little to no training and limited data, which is convenient during the early phases of the design process, where less detailed information is available at this early point in the development process. On the other hand, the MDI or the MCPD are more data and calculation demanding, i.e., applying these c-indicators requires access to more detailed data, but they can guide further on the detailed design of products. In between, the CCET or the CPI, and their respective calculation spreadsheets, appear to be intermediate and commendable solutions to both support decision making to design circular product and compare concepts, while being simple enough to enhance the understanding of non-expert designers on the circular economy concept.

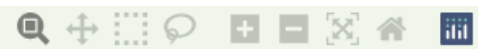

Requirements definition (second)

Conceptual design (second)

Detailed design (second)

Designs comparison (second)

Product monitoring (second)

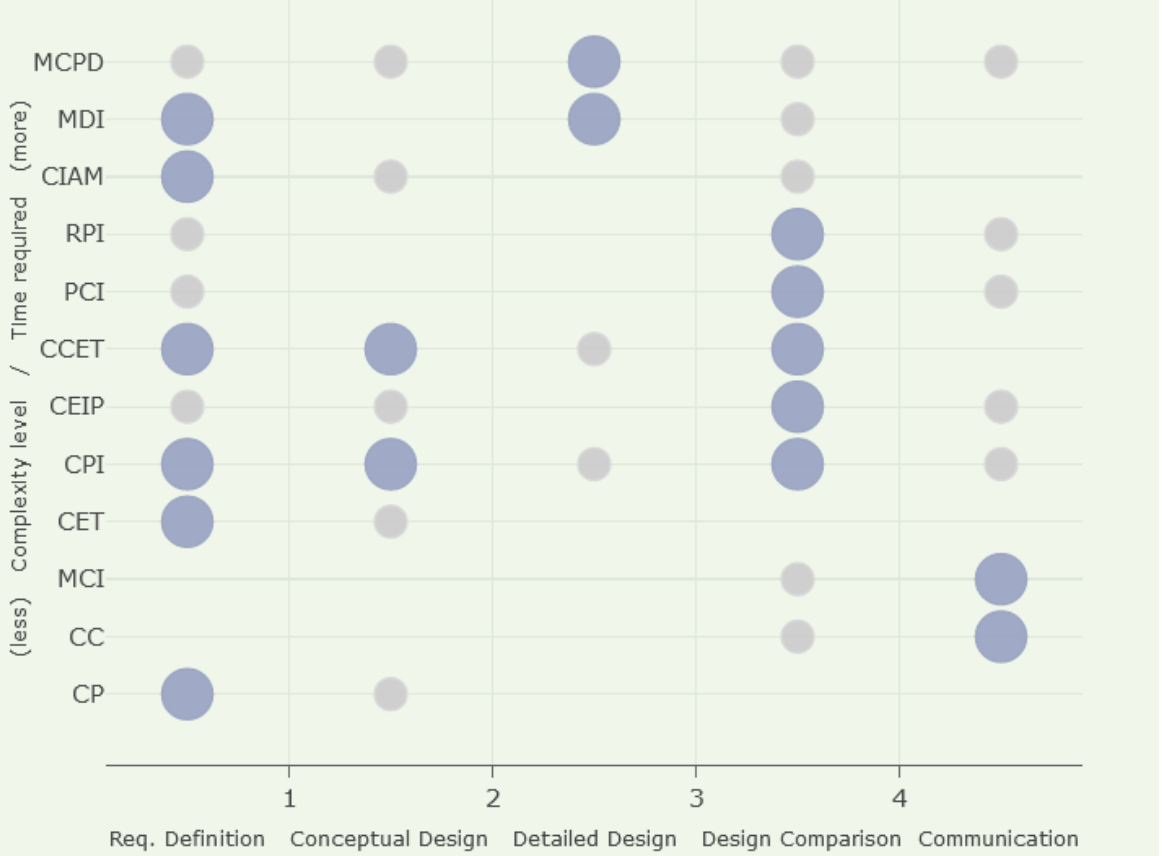

FIGURE 2: WEB-BASED TOOL TO VISUALIZE AND SELECT C-INDICATORS DURING THE PRODUCT DESIGN PROCESS 


\subsection{Illustrative examples to design for circularity}

Here, concrete examples - for each of the five steps of the engineering design process - are provided on how ad hoc cindicators can guide the circular design of products. In practice, in the early stage of product design and development, several cindicators, coming with their circularity assessment tools based on a set of circular design guidelines, are particularly relevant for circular economy-related requirements definition, to set circular goals, as well as to create and refine the concepts [36].

First, the questions of the CEIP Excel-based tool can guide circularity-based requirements definition, for example: Q1 "Is the product made from recycled/reused material?" can drive the description of requirements related to the total weight of the product comes from non-virgin material sources, reused, and recycled sources; Q6 "What packaging is being used?" orients towards six possible options, namely (i) packaging is not recyclable, (ii) packaging made from multiple materials and is recyclable (iii) packaging made only from recycled content,, (iv) packaging made only from paper or cardboard, (v) packaging reused multiple times (including rental), and (vi) no packaging required; Q9 "Can the product be repaired?" evaluates the repair options for the product, from manufacturer/retailer repair services to do-it-yourself repair.

Second, for the generation of circular design concepts, the 20 attributes of the CPI that are used to score the circularity performance can be insightful. In particular, within building block \#1 of this tool "Circular Product Design", several attributes are guiding the proper design of circular-ready products, e.g.: attribute \#1 "Materials selection and combination compatibility," questioning the technical recyclability of materials combination, as well as the potential material contamination (with coating, paints, and material mixing); attribute \#3 "Design for disassembly and easy end-of-life sorting" addressing the joints and connections types, as well as their accessibility for easy dismantling, maintenance or repair.

Third, for more detailed designs, even if it is currently not extensively covered by extant c-indicators, the MCPD indicator is composed of four design variables on which a practitioner can act to monitor product circularity performance, namely: design yield, functional unit, mass, material degradation after use. Moreover, the MDI integrates into a single calculation chemical and mechanical durability, incorporating parameters such as mechanical strength, flammability resistance, and even resistance to ultraviolet radiation, resistance to water, or resistance to organic solvents.

Fourth and fifth, the CC is a useful resource to make strategic decisions, design comparisons, and product monitoring. It can help designers, materials engineers, and product managers to answer the questions "What are the consequences of changes for the circularity of a product?" without lengthy analysis. Importantly, this tool can show the circularity consequences of fundamental design decisions before costly investments or consequential decisions have been made. Similarly, the MCI only requires a few inputs and is best used to quickly compare and select materials alternatives, as well as a communication or benchmarking tool, as it synthesized the complexity of material or product circularity performance in a single, intelligible and manageable indicator.

Last but not least, as depicted in Figure 2, the same cindicator can, of course, be suitable for multiple phases of the design process. The list of questions to compute the CPI, CEIP, or CCET can be useful to define CE-oriented requirements, and the circularity scores can be used to rank and identify best designs, as well as to monitor product's circularity to a certain extent. Also, note that few studies published recently provide both illustrative and real-world use cases on how c-indicators have been used to assess, monitor, and improve the circularity performance of products, e.g.: the CPI applied on a catalytic converter used in heavy-duty off-road vehicles and containing a non-negligible amount of precious metals [37], the CEPI and MCI on a tidal energy device [38], or even a prosthetic finger made of polymer materials demonstrating the usefulness of the MDI [33].

\section{CONCLUSION AND PERSPECTIVES}

Decisions made during the early design stages - such as material selection, assembly method, component accessibility for maintenance - can significantly influence a given product's quality, cost, sustainability, and circularity performance over its lifecycle. Yet, it appears that the circularity performance is often overlooked in the early stages of product design and development [2]. Building up on the momentum around the circular economy concept and the numerous circularity indicator developed in recent years, the present paper helps understand how ad hoc product-centric circularity indicators and their assessment framework can support circular design. It explains and illustrates how new c-indicators can be applied in the product design process, to help product architects or material scientists navigate and influence the circularity potential positively by making sound design, material, and architecture choices on the products they develop. Twelve c-indicators coming with practical tools have been identified, synthesized, and mapped along a generalized design process to support industrial practitioners (designers, material engineers, product development leads) designing more circular products and systems. While the standardization of circular economy indicators is an area of ongoing work (see ISO/TC 323/WG 3 "Measuring Circularity"), this research contributes to bringing further clarity to the current myriad of c-indicators, and therefore identify, select and use the right tools for a given situation (in the present case, during the engineering design process).

The thorough analysis on the current state of productfocused circularity indicators leads to two promising lines of work for future research: the first one is on how to foster the adoption of such c-indicators and tools in industrial practices; the second one is on the connection between circularity and sustainability performance, e.g., to systematically make sure a circular design is profitable, socially-acceptable and environmentally-friendly in the long run. In practice, it is key to: (i) further experimenting these c-indicators and associated tools with industrial practitioners such as designers, engineers, or managers (and document and report on these case studies, in 
order to disseminate good practices); (ii) connect the circularity performance of a given product with the performance of the company that develops this product (n.b. the Circular Transition Indicators by the World Business Council for Sustainable Development or Circulytics by the Ellen MacArthur Foundation are two company-level circular economy measurement tools that have been developed lately); (iii) integrate such c-indicators with the design tools that are used more broadly during the design process, such as computer-aided design programs making the detailed design phase more efficient [19]; lastly, (iv) link and combined complementary design methods and tools to measure the impact on sustainability as part of the design method [39], and in fine to develop better design concepts and product solutions in terms of circularity and sustainability performance [23, 40-42].

\section{REFERENCES}

[1] Schroeder, P., Anggraeni, K., and Weber, U., 2019, “The relevance of circular economy practices to the sustainable development goals," Journal of Industrial Ecology, 23(1), pp. 77-95.

[2] Kamp Albæk, J., Shahbazi, S., McAloone, T.C., and Pigosso, D.C., 2020, "Circularity evaluation of alternative concepts during early product design and development," Sustainability, 12(22), 9353.

[3] Dokter, G., Thuvander, L., and Rahe, U., 2021, "How circular is current design practice? Investigating perspectives across industrial design and architecture in the transition towards a circular economy," Sustainable Production and Consumption, 26, pp. 692-708.

[4] Esmaeilian, B., Behdad, S., and Wang, B., 2016, "The evolution and future of manufacturing: A review," Journal of Manufacturing Systems, 39, pp. 79-100.

[5] Ramani, K., Ramanujan, D., Bernstein, W.Z., et al., 2010, "Integrated sustainable life cycle design: a review," Journal of Mechanical Design, 132(9).

[6] Cong, L., Zhao, F., and Sutherland, J.W., 2019, "A design method to improve end-of-use product value recovery for circular economy," Journal of Mechanical Design, 141(4).

[7] Waas, T., Hugé, J., Block, T., Wright, T., BenitezCapistros, F., and Verbruggen, A., 2014, "Sustainability assessment and indicators: Tools in a decision-making strategy for sustainable development," Sustainability, 6(9), pp. 55125534.

[8] Saidani, M., Cluzel, F., Leroy, Y., and Yannou, B., 2019, "Testing the robustness of circularity indicators: empirical insights from workshops on an industrial product," Proceedings of the Design Society: International Conference on Engineering Design, 1(1), pp. 3401-3410, Cambridge University Press.

[9] Saidani, M., Kim, H., Cluzel, F., Leroy, Y., and Yannou, B., 2020, "Product circularity indicators: what contributions in designing for a circular economy?" Proceedings of the Design Society: DESIGN Conference, 1(1), pp. 2129-2138, Cambridge University Press.

[10] Kristensen, H.S., and Mosgaard, M.A., 2020, "A review of micro level indicators for a circular economy-moving away from the three dimensions of sustainability?" Journal of Cleaner Production, 243, 118531.

[11] Figge, F., Thorpe, A.S., Givry, P., Canning, L., and Franklin-Johnson, E., 2018, "Longevity and Circularity as Indicators of Eco-Efficient Resource Use in the Circular Economy," Ecological Economics, 150, pp. 297-306.

[12] Linder, M., Sarasini, S. and van Loon, P., 2017, "A Metric for Quantifying Product-Level Circularity," Journal of Industrial Ecology, 21, pp. 545-558.

[13] Alamerew, Y.A., Kambanou, M.L., Sakao, T., and Brissaud, D., 2020, "A Multi-Criteria Evaluation Method of Product-Level Circularity Strategies," Sustainability, 12(12), 5129.

[14] Thurston, D., and Behdad, S., 2020, "Sustainability and Life Cycle Product Design," Women in Industrial and Systems Engineering, pp. 517-540, Springer, Cham.

[15] Reike, D., Vermeulen, W.J.V., and Witjes, S., 2018, "The circular economy: New or Refurbished as CE 3.0? Exploring Controversies in the Conceptualization of the Circular Economy through a Focus on History and Resource Value Retention Options," Resources, Conservation and Recycling, 135, pp.246-264.

[16] Vanegas, P., Peeters, J. R., Cattrysse, D., et al., 2018, "Ease of disassembly of products to support circular economy strategies," Resources, Conservation and Recycling, 135, pp. 323-334.

[17] Razza, F., Briani, C., Breton, T., and Marazza, D., 2020, "Metrics for quantifying the circularity of bioplastics: The case of bio-based and biodegradable mulch films," Resources, Conservation and Recycling, 159, 104753.

[18] Heisel, F., and Rau-Oberhuber, S, 2020, "Calculation and evaluation of circularity indicators for the built environment using the case studies of UMAR and Madaster," Journal of Cleaner Production, 243, 118482.

[19] Dym, C.L. and Little, P., 2009, "Engineering Design," 3rd ed. New York, N.Y., John Wiley \& Sons, Inc.

[20] Pahl, G., and Beitz, W., 2013, "Engineering design: a systematic approach," Springer Science \& Business Media.

[21] Ulrich, K.T., 2003, "Product design and development," Tata McGraw-Hill Education.

[22] Bovea, M.D., and Pérez-Belis, V., 2012, “A taxonomy of ecodesign tools for integrating environmental requirements into the product design process," Journal of Cleaner Production, 20(1), pp. 61-71.

[23] de Oliveira, C.T., Dantas, T.E.T., and Soares, S.R., 2021, "Nano and Micro Level Circular Economy Indicators: Assisting decision-makers in circularity assessments", Sustainable Production and Consumption, 26, pp. 455-468.

[24] Roos Lindgreen, E., Salomone, R., and Reyes, T., 2020, "A Critical Review of Academic Approaches, Methods and Tools to Assess Circular Economy at the Micro Level," Sustainability, 12(12), 4973.

[25] ResCoM-Resource Conservative Manufacturing, 2017, "Circularity Calculator," accessed February 15, 2021, https://www.rescoms.eu/platform-and-tools.html. 
[26] Cayzer, S., Griffiths, P., and Beghetto, V., 2017, "Design of indicators for measuring product performance in the circular economy. International Journal of Sustainable Engineering," 10(4-5), pp. 289-298.

[27] Evans, J., and Bocken, N., 2013, "Circular Economy Toolkit," accessed February 15, 2021, http://circulareconomytoolkit.org/

[28] ENEL, 2019, "Circular Index from CirculAbility Model," accessed February 15, 2021, https://www.enel.cl/en/sustainability/circular-

economy/circulability-model.html

[29] ResCoM-Resource Conservative Manufacturing, 2017, "Circularity Pathfinder," accessed February 15, 2021, https://www.rescoms.eu/platform-and-tools.html.

[30] Saidani, M., Yannou, B., Leroy, Y., and Cluzel, F., 2017, "Hybrid top-down and bottom-up framework to measure products' circularity performance," International Conference on Engineering Design, ICED 17, Aug. 2017, University of British Columbia, Vancouver, Canada.

[31] Ellen MacArthur Foundation, and Granta Design, 2015, "Circularity Indicators, An approach to measuring circularity," Isle of Wight and Cambrigde, UK.

[32] Dwek, M., 2017, "Integration of material circularity in product design," PhD Thesis, in Environmental and Society, at Université Grenoble Alpes, France.

[33] Mesa, J., González-Quiroga, A., and Maury, H., 2020, "Developing an indicator for material selection based on durability and environmental footprint: A Circular Economy perspective," Resources, Conservation and Recycling, 160, 104887.

[34] Bracquené, E., Dewulf, W., Duflou, J.R., 2020, "Measuring the performance of more circular complex product supply chains," Resources, Conservation and Recycling, 154, 104608.

[35] Park, J.Y., and Chertow, M.R., 2014, "Establishing and testing the "reuse potential" indicator for managing wastes as resources," Journal of environmental management, 137, pp. 4553.

[36] Shahbazi, S., Jönbrink, A.K., Hjort Jensen, T., Pigosso, D.C.A., and McAloone, T.C., 2020, "Circular Product Design and Development: CIRCit Workbook 3", ISBN: 978-87-7475604-0, Technical University of Denmark, 44.

[37] Saidani, M., Kendall, A., Yannou, B., Leroy, Y., and Cluzel, F., 2019, "Closing the loop on platinum from catalytic converters: Contributions from material flow analysis and circularity indicators," Journal of Industrial Ecology, 23(5), pp. 1143-1158.

[38] Corona, B., Shen, L., Reike, D., Carreón, J.R., and Worrell, E., 2019, "Towards sustainable development through the circular economy-A review and critical assessment on current circularity metrics," Resources, Conservation and Recycling, 151, 104498.

[39] Faludi, J., Hoffenson, S., Kwok, S.Y., et al., 2020, "A research roadmap for sustainable design methods and tools," Sustainability, 12(19), 8174.
[40] He, B., Li, F., Cao, X., and Li, T., 2020, "Product sustainable design: a review from the environmental, economic, and social aspects," Journal of Computing and Information Science in Engineering, 20(4).

[41] Saidani, M., Kim, H., Yannou, B., Leroy, Y., and Cluzel, F., 2019, "Framing Product Circularity Performance for Optimized Green Profit," Proceedings of the ASME 2019 International Design Engineering Technical Conferences and Computers and Information in Engineering Conference, Volume 4: 24th Design for Manufacturing and the Life Cycle Conference; 13th International Conference on Micro- and Nanosystems, Anaheim, California, USA, August 18-21, 2019.

[42] Kwak, M., and Kim, H, 2013, "Economic and environmental impacts of product service lifetime: a life-cycle perspective," In Product-Service Integration for Sustainable Solutions, Springer, Berlin, Heidelberg, pp. 177-189. 